The Journal of Animal \& Plant Sciences, 31(4): 2021, Page: 1212-1216

ISSN (print): 1018-7081; ISSN (online): 2309-8694

$\underline{\text { Short Communication }}$

\title{
ECONOMIC EVALUATION OF BOAR SEMEN PRODUCTION UNIT FOR SMALLHOLDER PIG PRODUCTION SYSTEM
}

\author{
K. Govindasamy*, T. Chutia, M. Rahman, M. K. Kalita and R. Dewry \\ Division of Animal Production, ICAR Research Complex for NEH Region, Umiam, Meghalaya - 793 103, India \\ *Corresponding author: Email: velvet.2007@rediffmail.com
}

\begin{abstract}
Artificial insemination (AI) is widely practiced in many countries for enhancing pig productivity. Success of this technique is dependent upon quality boar semen production and profitability of the farm. Besides increasing the productivity of nondescript pigs reared under smallholder pig production system, the establishment of boar semen production unit has potential scope for entrepreneurship development in the north eastern part of India. The present study investigated detailed requirements for establishment of boar semen production unit and their cost benefit analysis based on the retrospective study of five years data of a boar semen production unit for backyard smallholder pig production system. A total of 65 healthy male piglets were chosen during weaning out of which 54 pigs were selected for training for semen collection based on their breeding soundness. A total of 1820 ejaculates were collected from the trained boars and AI doses prepared after evaluation. The extended semen was preserved in incubator at $15-18^{\circ} \mathrm{C}$ and used for insemination within three days of storage in smallholder pig producers in the region. The results revealed that $79.62 \%$ of boars were successfully trained to mount a dummy sow for semen collection. The average gel-free ejaculatory volume, sperm motility and sperm concentration were $214.26 \pm 9.23 \mathrm{ml}, 85.00 \pm 0.82 \%$ and $258.50 \pm 9.19 \mathrm{million} / \mathrm{ml}$ respectively. Average of 10 ejaculates was collected from each boar in a month, which yielded 110 AI doses per month. Average semen production cost per AI dose was INR 35.78, including the chemical cost (INR 3.39) for extender. Average insemination cost per sow/gilts in small holder production system was INR 455.79, which included the catheter and transport cost. The cost benefit analysis of boar semen production unit with five boars revealed the income generation of INR 31688.89 per month. The present study demonstrates the feasibility and profitability of boar semen production unit for the backyard smallholder pig production system.
\end{abstract}

Keywords: boar, semen, production, economic analysis, smallholder pig production, entrepreneurship

https://doi.org/10.36899/JAPS.2021.4.0320

Published online January 30, 2021

\section{INTRODUCTION}

Among the livestock, pigs are generally considered as the most prolific species exclusively reared for meat purpose. Pig farming is playing an important role in improving the socio-economic status of a sizable population of south Asian countries, including the north east India. Therefore, pig is the popular and valued livestock species in this region. These pigs are mostly reared under small holder production system, where every household keeps 1 to 2 pigs in backyard (Chauhan et al., 2016). However, this production system revealed low profitability to the pig farmers due the poor productivity of non-descript pigs and breeding constraints viz. lack of availability of quality boars and high mating costs. Shortage of breeding boars is mainly due to early castration of male piglets for fattener pig production (Kadirvel et al. (2013). Limited numbers of farmers keep breeding boar as a "community boar" for natural mating and charge an amount of INR 1200 to 1500 or one or two piglets per natural service (Kadirvel et al., 2013). To improve the productivity through cross breeding nondescript pigs as well as to overcome the breeding constraints in the traditional production system, Artificial insemination (AI) is the cost-effective option. The multiple advantages of AI with liquid semen and its feasibility and popularity in small holder production system have been already reported (Kadirvel et al., 2013). In the recent past, $\mathrm{AI}$ has been gaining popularity in small holder pig production system and growing small scale commercial pig farms in India and south Asian countries (Visalvethaya et al., 2011; Kadirvel et al., 2013). In this context, availability of the superior quality boar semen is the major bottleneck. Establishment of a boar semen production unit could be advantageous for marketing of superior quality semen. There is a potential scope on entrepreneurship development in boar semen production and marketing for both small holder pig production system and small scale/semi-commercial pig farms in the region. Therefore, the present study investigated detailed requirements for establishment of a boar semen production unit and their cost benefit analysis based on the retrospective study. 


\section{MATERIALS AND METHODS}

Study location and experimental animals: The present study was carried out at the boar semen production and artificial insemination unit, ICAR-Research Complex for North-Eastern Region, Umiam, Meghalaya, India, during the period from 2014 to 2018 . A total of 65 clinically healthy male piglets irrespective of breed, one from each litter were selected at the time of weaning ( 45 days of age) for future breeding stock. The pigs were reared under intensive management system and mature boars were kept in individual pens. Piglets fed commercial mess feed adlibitum as per standard recommendation. Pigs were fed equal meals twice daily at 8 am and $3 \mathrm{pm}$. Daily feeding rate was $4 \%$ of the pigs' live weight (Adeola, 2001). Drinking water was provided ad-libitum throughout the period. At the age of six months, 54 of these piglets were selected for training for semen collection based on their breeding soundness with respect to pedigree records, physical appearance and temperament in male behaviour exhibited during approach to the teaser. All the selected animals were reared individually in pen at least for one month before training. A dummy sow (IMV ${ }^{\circledR}$, France) was used for training the boars daily in the morning. During training, smearing of the dummy sow with the penile secretion, mimicking of the breeding sound, striking of the dummy and snout of the boar were followed. A total of 43 boars were successfully trained using the dummy sow.

Semen collection, evaluation, processing and AI: A total of 1820 ejaculates were collected from the trained boars by "Gloved hand method" in to a pre warmed $\left(38-40^{\circ} \mathrm{C}\right)$ thermos flask or sterilized plastic bottles covered with insulator (Levis and Reicks, 2005). The gel fraction was removed using a Buchner funnel. Semen was collected from the boar with minimum of three days interval or ten ejaculates in a month from each boar. Semen was evaluated for volume ( $\mathrm{ml}$ ), per cent sperm motility (visual assessment under microscope), percentage of live sperm (Eosin-Nigrosin stain) and sperm concentration (Hemocytometer method). Semen samples showing $\geq 70$ per cent sperm motility was used for further processing. Total of 67 semen ejaculates were discarded due to the poor quality from the total semen ejaculates. Extension of the semen was done using Beltsville Thawing Solution (BTS; Pursel and Johnson, 1975) based on sperm concentration, so that each insemination dose of $80 \mathrm{ml}$ contained three billion sperm. Then the required volume of extended semen was filled in sterile Golden Tip Bag $\left(G T B, I^{\circledR}{ }^{\circledR}\right.$, France) manually and sealed by electronic sealer. The packed semen was preserved in incubator at $15-18^{\circ} \mathrm{C}$ and used for insemination within three days of storage. The semen doses were exclusively used for insemination of female pigs reared by smallholder pig producers in the region. Once a sow/gilt showed signs of heat, the farmer informed to the facilitator who were directly communicate to inseminator group. Accordingly, packed semen with accessories was transported and inseminated estrous sows/gilts by golden pig catheter (IMV technologies, France). Total of 880 sows/gilts were inseminated at farmer doorstep in the small holder pig production system. Pregnancy rate, farrowing rate and litter size at birth were recorded after insemination.

Cost benefit analysis of semen production: In the present study the cost of chemicals, semen dose, feed and maintenance cost was calculated as per data for five years from the semen production and artificial insemination unit. The cost involvement in terms of fixed and variable cost for establishment of a boar semen unit having five breeding boar was calculated based on the average market price during the period in the region and income was calculated per annum.

\section{RESULTS AND DISCUSSION}

Elite boar is the primary component of a pig farm, thus selection of superior boar that enters into the semen production unit is very important. The conventional method of selection of boar is based on the phenotypic appearance and behaviour exhibited by the boar during mating. Selection of boars specific to the breed characteristics is carried out on the basis of their pedigree records, e.g. performance of sire and dam along with collateral relatives in terms of litter size at birth, litter size at weaning, growth rate and age at maturity. In the present study, 65 piglets were selected at weaning for future breeding; among these, $83.07 \%$ were found to be eligible for breeding and semen collection based on their physical and behavioural characteristics at six months of age. Based on the past data in the study, $79.62 \%$ of boars were trained successfully for semen collection over dummy sow and remaining $20.38 \%$ boars could not be trained even after two months of training (Table 1). Similar percentage of success in training for semen collection was recorded earlier (Estienne and Harper, 2000), however, higher rate $(90 \%)$ of success was recorded when prostaglandin $(25$ $\mathrm{mg}$ ) was administered to the boar 30 minutes before training ( Szuropet al., 2007).

In the present study, the mean gel-free volume $(\mathrm{ml})$, sperm motility (\%), live sperm count $(\%)$ and sperm concentration (million/ml) recorded were 214.26 \pm 9.23 , $85.00 \pm 0.82,81.70 \pm 3.68$ and $258.50 \pm 9.19$, respectively (Table 1). The parameters are in agreement with those recorded in earlier studies by Kumaresan et al. (2009), Chutia et al. (2017) and Chutia et al. (2019) were 210, $87.50,90.92 \& 278 ; 228.7,87.4,90.5 \& 339.2$ and 231.32 , $85.00,80.50 \& 179.87$, respectively. After insemination, the study recorded pregnancy rate of $77.7 \%$ and farrowing rate of $75.1 \%$. While mean letter size at birth was $8.72 \pm$ 0.53 in the smallholder pig production system. The farrowing rate and litter size recorded in the study is within 
the range reported in commercial pig farms (Lamberson and Safranski, 2000; Haugana et al., 2005; Kadirvel et al., 2013). In the past study demonstrated that AI offered significantly better fertility than natural mating in backyard pig farmers of Thailand (Am-in et al., 2010).

The present study also investigated the boar semen productivity and its economic analysis. It was found that minimum 10 ejaculates could be collected at three days interval from each boar in a month without affecting normal sperm concentration. An average of 11 AI doses could be prepared per ejaculate considering 3 billion sperm cells in $80 \mathrm{ml}$ of extended semen. Accordingly, minimum 110 AI doses were prepared per month per breeding boar. In the present study, BTS extender was used to prepare AI doses because its ingredients are easily available in the market and least expensive compared to other commercially available extenders. Semen can be preserved up to three days with BTS extender without marked reduction of sperm fertility (Kadirvel et al., 2016). The cost of semen production, including the extender cost, was INR 35.78 per dose. The cost of chemicals for preparation of $100 \mathrm{ml}$ extender was INR 3.39 (Table 2), which is cheaper than reported earlier by Rutten et al. (2000) i.e., \$0.20 INR 15.24. In the present study, artificial insemination was carried out with the liquid semen extended at farmer's doorstep in small holder pig production system. The average artificial insemination cost was INR 455.79 including semen cost, AI catheter, shipping (semen transportation) cost and insemination charges (Table 3). The insemination cost was 2-3 times lower when compared to the natural mating cost with community boar in traditional smallholder pig production system, where mating cost was INR 1200-1500 or provision of one or two piglets to the boar owner (Kadirvel et al., 2013). The major insemination cost in the present study was for semen transportation which can be reduced further by mobile-unit based AI delivery model and fixed time insemination following estrous synchronization keeping in view the distribution and density of pig population in small holder pig production system.

It is important to note that lack of quality breeding boar is the main constraint in the smallholder pig production system. In this context, we believe that establishment of boar semen production unit for AI will have significant impact on the traditional pig production. The data demonstrated an attractive generation of revenue through the boar semen production unit in the present study (Table 4). An average income of INR 31688.89 per month was obtained from the five boar semen production unit (Table 4). The commercialization of semen production in cattle, buffalo, sheep and goat has been established in the smallholder production system. Recently, Yuvraj and Sultan, two buffalo (Murrah) bulls from Haryana, India generated the income of INR 150000 from one ejaculate and the single frozen semen straw was sold @ INR 250-300 (Hindustan Times). Thus, establishment of boar semen production unit will facilitate self-employment generation to unemployed youth and also provide greater advantage to smallholder pig farmers in north east region of India.

Table 1. Breeding boars and their seminal characters.

\begin{tabular}{ll}
\hline Total male piglets stock & $\mathbf{6 5}$ nos. \\
\hline Selected boars for training $(6$ months) & 54 nos. $(83.07 \%)$ \\
Trained boars & 43 nos. $(79.62 \%)$ \\
Strained volume $(\mathrm{ml})$ & $214.26 \pm 9.23$ (Range: $120-310)$ \\
Gel mass volume $(\mathrm{ml})$ & $22.82 \pm 4.20$ ( Range: $9-40)$ \\
Sperm motility $(\%)$ & $85.00 \pm 0.82$ (Range: $75-95)$ \\
Live spermatozoa $(\%)$ & $81.70 \pm 3.68$ (Range: $70-86)$ \\
Sperm concentration $(\mathrm{million} / \mathrm{ml})$ & $258.50 \pm 9.19$ (Range: $220-385)$ \\
\hline
\end{tabular}

Table 2. Cost of chemicals (HIMEDIA ${ }^{\circledR}$, India) of BTS extender.

\begin{tabular}{lccc}
\hline Chemical Ingredients & $\begin{array}{c}\text { Cost of 500g pack } \\
\text { (INR) }\end{array}$ & Composition & $\begin{array}{c}\text { Price per 100 ml extender } \\
\text { (INR) }\end{array}$ \\
\hline D-glucose & 325.00 & $3.70 \mathrm{~g}$ & 2.40 \\
Tri-sodium citrate & 530.00 & $0.60 \mathrm{~g}$ & 0.60 \\
EDTA & 1170.00 & $0.125 \mathrm{~g}$ & 0.29 \\
Sodium bicarbonate & 265.00 & $0.125 \mathrm{~g}$ & 0.06 \\
Potassium chloride & 315.00 & $0.075 \mathrm{~g}$ & 0.04 \\
Distilled water up to & -- & $100 \mathrm{ml}$ & Total = 3.39 \\
\hline
\end{tabular}

Table.3. Production Cost (INR) of liquid semen extended with BTS and average artificial insemination cost in smallholder pig production system. 


\begin{tabular}{ll}
\hline No. of ejaculates per month/boar & $\mathbf{1 0}$ \\
\hline No. of semen dose/ejaculate & 11 \\
Total no. of semen dose/month & 110 \\
Cost of boar per month & 333.33 \\
(Cost of one Boar @ INR 12000.00 utilized for 3 years) & \\
Cost of feed/boar/month (3 kg/day @ INR 20/kg) & 1800.00 \\
Other maintenance cost of the boar/month & 300.00 \\
(including cleaning, medical and veterinary aids) & \\
Cost of extenders/month for 110 dose (Cost of BTS @ INR3.39/dose) & 372.90 \\
Cost of equipments and electricity etc., per month @ INR 3.0/dose & 330.00 \\
Cost of manpower for semen processing/boar/month & 800.00 \\
(One person for 10 boar @ INR 8000/month) & \\
Total production cost for 110 dose/month & 3936.23 \\
Total semen production cost/dose & $\mathbf{3 5 . 7 8}$ \\
Cost of Golden pig AI Catheter & 20.00 \\
Semen Transportation/shipping cost & 300.00 \\
Insemination Charge & 100.00 \\
Total cost of Artificial Insemination & $\mathbf{4 5 5 . 7 9}$ \\
Pregnancy rate & $77.7 \%$ \\
Farrowing rate & $75.11 \%$ \\
Mean litter size at birth & $8.72 \pm 0.53$ \\
\hline
\end{tabular}

Table 4. Economic analysis of boar semen production with five boar unit (in INR).

\begin{tabular}{|c|c|c|c|}
\hline \multirow{2}{*}{\multicolumn{4}{|c|}{$\begin{array}{l}\text { Particulars } \\
\text { Fixed cost }\end{array}$}} \\
\hline & & & \\
\hline $\begin{array}{l}\text { Constriction of boar shed with concrete floor for } 5 \text { boars }(100 \\
\text { square feet floor space per boar } @ \text { INR } 180 / \text { square feet) }\end{array}$ & 90000.00 & -- & -- \\
\hline Cost of 5 boars of three months age $@$ Rs $3000 /$ boar & 15000.00 & -- & -- \\
\hline Cost of equipment & & & \\
\hline $\begin{array}{l}\text { Autoclave, Hot air oven, BOD incubator, water bath, simple } \\
\text { microscope, water distillation unit, weighing balance }\end{array}$ & 300000.00 & -- & -- \\
\hline Dummy sow & 70000.00 & -- & -- \\
\hline Plastic and glassware and chemicals & 50000.00 & 50000.00 & 50000.00 \\
\hline \multicolumn{4}{|l|}{ Variable/working/operational cost } \\
\hline $\begin{array}{l}\text { Feed cost /year for } 5 \text { boar } \\
(3 \mathrm{~kg} \text { feed/day/boar } @ \text { INR 20.00/ kg feed) }\end{array}$ & 109500.00 & 109500.00 & 109500.00 \\
\hline Medicine and veterinary aid & 5000.00 & 5000.00 & 5000.00 \\
\hline $\begin{array}{l}\text { One part time labour for cleaning and other Management @INR } \\
70 / \text { day for } 365 \text { days }\end{array}$ & 21900.00 & 21900.00 & 21900.00 \\
\hline Miscellaneous & 4000.00 & 4000.00 & 4000.00 \\
\hline $\begin{array}{l}\text { Cost for one technical person for semen processing @ INR } 8000 \\
\text { /month }\end{array}$ & 96000.00 & 96000.00 & 96000.00 \\
\hline Total cost (A) & 761400.00 & 286400.00 & 286400.00 \\
\hline \multicolumn{4}{|l|}{ Income (B) } \\
\hline No. of semen dose/boar/years & 660 & 1320 & 1320 \\
\hline Total semen dose/year & 3300 & 6600 & 6600 \\
\hline Income from sale of semen dose $@$, INR150/dose & 495000.00 & 990000.00 & 990000.00 \\
\hline Profit (B-A) & -266400.00 & 703600.00 & 703600.00 \\
\hline Total profit in Three years & 1140800.00 & & \\
\hline Profit per month & 31688.89 & & \\
\hline
\end{tabular}

Conclusion: The present study demonstrated feasibility and profitability of boar semen production unit for smallholder pig production system in the north region of India, where pig is the most important livestock species.
There is a potential scope for entrepreneurship development through establishment of small boar semen production unit which enhances the productivity of pigs reared under smallholder pig production trough AI. It will 
also increase the profitability of small holder pig farmers by reducing the mating cost, as well as increasing the productivity of non-descript pigs through their genetic improvement in small holder pig production system.

Acknowledgements: The authors thankfully acknowledge the Indian Council of Agricultural Research (ICAR) and Director, ICAR Complex for NEH Region for providing the facilities to conduct the research.

Conflict of Interest Declaration: The authors declare that there is no conflict of interest for this study.

\section{REFERENCES}

Adeola, O. (2001). Digestion and balance techniques in pigs. In: Swine Nutrition, 2nd ed. (Eds. A. J. Lewis and L. L. Southern). CRC Press, New York, USA: 903-916.

Am-in, N., W. Tantasuparuk, and M. Techakumphu (2010). Comparison of artificial insemination with natural mating on smallholder farms in Thailand, and the effects of boar stimulation and distance of semen delivery on sow reproductive performance, Trop. Anim. Health Prod. 42: 921 924.

Chauhan, A., B.H.M. Patel, R. Maurya, S. Kumar, S. Shukla, and S. Kumar (2016). Pig production system as a source of livelihood in Indian scenario: an overview. J. Sci. Environ. Technol. 5(4): 2089-2096.

Chutia, T., F.A. Ahmed, K. Lalrintluanga, G. Kalita, J.M. Gali, P. Roychoudhury, P. Mayengbam, and J.K. Chaudhury (2019). Coparative analysis of seminal characters of exotic and cross-bred boars. Haryana Vet. 58 (S.I.): 53-55.

Chutia, T., M.K. Tamuli, R.K. Biswas, B.C. Deka, S. Sinha, and J. Goswami (2017). Interrelations of service behaviour and seminal attributes of Hampshire boars. Indian J. Anim. Reprod. 38 (2): 28-30.

Estienne, M.J. and A.F. Harpe (2000). PGF 2 alpha facilitates the training of sexually active boars for semen collection. Theriogenology 54(7):108792.

Haugana, T., O. Reksen, Y.T.Grohn, A. H.Gaustad, and P. P. Hofma (2005). A retrospective study on effects of storage time of liquid boar semen on reproductive performance in Norwegian swine, Theriogenology, 64: $891-901$.
Hindustan Times (https://www.hindustantimes.com/indianews/meet-yuvraj-and-sultan-rajasthan-s-superbulls-whose-semen-is-worth-lakhs-ofrupees/storyCug2pgrJvCFXIpONR7P4mL.html.) May 25, 2017.

Kadirvel, G., A. Kumaresan, A. Das, K.M. Bujarbaruah and S.V. Ngachan (2013). Artificial insemination of pigs reared under smallholder production system in north-eastern India: Success rate, genetic improvementand monitory benefit. Trop. Anim. Health Prod. 45: 679-686.

Kadirvel, G., P. Perumal, T. Sarath, A. Jerome, S. Naskar, A. Das, H. Dhilruba, and S.K. Baishya (2016). Efficacy of different extenders on sperm characteristics and fertility in crossbred pigs of north-eastern India. Vet. Arhiv. 86 (4): 515-528.

Kumaresan, A., G. Kadirvel, K.M. Bujarbaruah, R.K. Bardoloi, A. Das, S. Kumar, and S. Naskar (2009). Preservation of boar semen at 18 degree $\mathrm{C}$ induces lipid peroxidation and apoptosis like changes in spermatozoa. Anim. Reprod. Sci. 110: 162-171.

Lamberson, W.R., and T.J. Safranski (2000). A model for economic comparison of swine insemination programs, Theriogenology 54: 799 - 807.

Levis, D.G and D.L. Reicks (2005). Assessment of sexual behavior and effect of semen collection pen design and sexual stimulation of boars on behavior and sperm output a review. Theriogenology 63:630-42.

Pursel, V.G. and L.A. Johnson (1975). Freezing of boar spermatozoa: Fertilizing capacity with concentrated semen on a new thawing procedure. J. Anim. Sci. 40:99.

Rutten, S.C., R.B. Morrison, and D. Reicks (2000). Boar stud production analysis. Swine Health Prod. 8 (1): 11-14.

Szurop, I., W. Jöchle, and A. Nagy (2007). Stimulation of Libido in Pubertal and Mature Boars with Prostaglandin F2 $\alpha$

analogs:clinical observations. Reprod. Domest. Anim. 21(2): 083-086.

Visalvethaya, W., W. Tantasuparuk, and M. Techakumphu (2011). The development of a model for artificial insemination by backyard pig farmers in Thailand. Trop. Anim. Health Prod. 43(4): 787-793. 